\title{
Dynamic exacerbation in inflammation and oxidative stress during the formation of peritendinous adhesion resulted from acute tendon injury
}

Pengfei $\mathrm{Li}^{1+}$, Haiying Zhou ${ }^{2+}$, Tian $\mathrm{Tu}^{1}$ and Hui Lu${ }^{2 *}$ (D)

\begin{abstract}
Background: Peritendinous adhesion is among the common complications after tendon injury. Numerous studies have been carried out to prevent its formation, including modifications of surgical procedures, postoperative cares, application of medicines, etc. This study dynamically monitored fluctuations of inflammation, state of oxidative stress, and histopathologic changes around injured tendon to provide theoretical basis for further exploration in mechanisms of peritendinous adhesion formation.

Methods: Eighteen mature Sprague-Dawley male rats were randomly allocated into 6 equal groups. Compared with control and sham group, every rat's right hind Achilles tendon in experimental groups was cut and repaired by the modified Kessler technique. Besides control and sham group, samples of tendon margin and serum were collected at different time points after the surgery. Content of TNF- $\alpha$, IL-1 $\beta$, and TGF- $\beta$ were assayed in harvested serum. Reactive oxygen species (ROS) were detected, expression levels of related genes (IL-1 $\beta$, IL-6, SOD1, SOD2, COL1, HIF1A) were quantified by QPCR, and various histopathological evaluations were performed.

Results: Indicators (TNF- $\alpha$, IL-1 $\beta$, TGF- $\beta 1$, ROS) were noticed to have a similar trend of significant rising $24 \mathrm{~h}$ after the surgery except TGF- $\beta$ which was rising $72 \mathrm{~h}$ later. So were the expression trends of IL-1 $\beta$, IL-6, SOD1, SOD2, and COL1. HIF1A, inversely correlated with SOD2, showed the progressive relief of regional tissue hypoxia. Histological evaluation showed the same tendency that fibrosis and inflammation were getting serious $48 \mathrm{~h}$ later after the surgery.

Conclusions: Inflammation, oxidative stress in injured tendon resulted from acute trauma, would be getting intense in $24 \mathrm{~h}$. Peritendinous adhesion emerges and aggravates after $48 \mathrm{~h}$. Thus, prompt efficient measures are advised to be taken after the injury as soon as possible.
\end{abstract}

Keywords: Peritendinous adhesion, Acute tendon injury, Tendon surgery, Reactive oxygen species, Inflammation, Dynamic exacerbation

\footnotetext{
* Correspondence: huilu@zju.edu.cn

${ }^{\dagger}$ Pengfei Li and Haiying Zhou contributed equally to this work. 2Department of Orthopedics, The First Affiliated Hospital, College of Medicine, Zhejiang University, \#79 Qingchun Road, Hangzhou 310003, Zhejiang Province, China

Full list of author information is available at the end of the article
}

(c) The Author(s). 2021 Open Access This article is licensed under a Creative Commons Attribution 4.0 International License, which permits use, sharing, adaptation, distribution and reproduction in any medium or format, as long as you give appropriate credit to the original author(s) and the source, provide a link to the Creative Commons licence, and indicate if changes were made. The images or other third party material in this article are included in the article's Creative Commons licence, unless indicated otherwise in a credit line to the material. If material is not included in the article's Creative Commons licence and your intended use is not permitted by statutory regulation or exceeds the permitted use, you will need to obtain permission directly from the copyright holder. To view a copy of this licence, visit http://creativecommons.org/licenses/by/4.0/. The Creative Commons Public Domain Dedication waiver (http://creativecommons.org/publicdomain/zero/1.0/) applies to the data made available in this article, unless otherwise stated in a credit line to the data. 


\section{Background}

Peritendinous adhesion is one of the most common complications following tendon injuries [1]. It prevents tendon excursion during the healing process, and eventually cause the reduction of joint motion and result in poor function [2, 3]. Functional disturbances prolong rehabilitation, give rise to psycho-socioeconomic problems, and require reoperation $[1,4,5]$. Previously numerous methods have been carried out to prevent adhesion formation, including modifications of surgical techniques, use of mechanical barriers, systemic or local application of medications, and postoperative physical therapy [1, 2, 5-12]. Though most of them got positive results, the specific mechanisms underneath remain poorly explored. It is believed that adhesion would decrease and joint gliding be facilitated if peritendinous inflammation could be prevented in the repair period [5, $13,14]$. What is more, hypoxia-induced oxidative stress following tissue injury might be responsible for starting the process of fibrosis and leading to unnecessary tissue adhesion [15-17]. Though many researchers have explored about reactive oxygen species (ROS) [17, 18], there is barely any exploration connected them with trauma, especially tendon injuries.

In order to find the inner relationship of inflammation, oxidative stress and fibrosis of injured tendon, we dynamically monitored fluctuations of inflammatory state, reactive oxygen species, and histopathologic changes around injured tendon in the hope of providing theoretical basis for further exploration in the mechanisms of peritendinous adhesion formation and future treatment application, such as precise drug delivery.

\section{Materials and methods}

\section{Rat Achilles tendon injury model}

All animal experiments were performed according to the guidelines outlined by the National Technical Committee on Laboratory Animal Science of the Standardization Administration of China and approved by the Animal Welfare and Research Ethics Committee in the First Affiliated Hospital, College of Medicine, Zhejiang University (reference number:2019(990)).

Eight-week-old Sprague-Dawley male rats were housed with freely available commercial rat chow and tap water and maintained on a 12-h light/dark cycle. They were raised to acclimate for 2 weeks prior to surgery. Anesthesia was implemented with intraperitoneal injection of $10 \%$ chloral hydrate $(0.3 \mathrm{ml} / 100 \mathrm{~g})$ after $12 \mathrm{~h}$ of fasting. Lying supine, all limbs were fixed except the right hind ones which were reserved for anastomosis of Achilles tendon. Mid-lateral incision of $3 \mathrm{~cm}$ was made in the forelimb to expose the Achilles tendon. Then, sharply sever the tendon obliquely in the middle and anastomose tendon ends using modified Kessler's method with 5-0 Ti-Cron non-absorbable sutures (COVIDIEN, Langhorne, PA, USA). Finally, skin was closed with 5-0 Surgipro sutures (COVIDIEN, Langhorne, PA, USA) [11]. All surgical procedures were performed by the same surgeon (Fig.1).

\section{Grouping and harvesting}

Eighteen Sprague-Dawley (SD) male rats weighing around $350 \mathrm{~g}$ were equally allocated into 6 groups. They were treated as follows: group 1 (control), no intervention; group 2 (sham), the identical skin incisions were made and closed with the tendon intact; groups 3, 4, 5, and 6 (tendon surgery), all rats went through the Achilles tendon surgery.

The serum and samples of the tendon tissue in every group were arranged to be harvested as follows: group 1, same time with group 2; group 2, $72 \mathrm{~h}$ after the fake surgery; group 3, $6 \mathrm{~h}$ after the tendon surgery; group 4, 24 $\mathrm{h}$ after the tendon surgery; group 5, $48 \mathrm{~h}$ after the tendon surgery; group $6,72 \mathrm{~h}$ after the tendon surgery.

\section{Gross observation and macroscopic evaluation of tendon adhesion}

The mental state, activity, fur, weight, and wound healing of SD rats were dynamically observed. Before sacrificing the animals, the repaired Achilles tendon was thoroughly exposed and visually examined for its healing and signs of inflammation and granulation tissue hyperplasia. The criteria for evaluation of peritendinous adhesion described by Tang et al. [11, 19] were adopted in our measurement Table 1

\section{Inflammation evaluation}

To evaluate the degree of inflammation the injuries caused, content of TNF- $\alpha$, IL- $1 \beta$, and TGF- $\beta 1$ in the serum were chosen as the key indicators. Then content of the indicators was detected by means of enzymelinked immunosorbent assay (ELISA).

\section{Oxidative stress}

The reactive oxygen species in the collected samples of each group were detected to measure the level of oxidative stress according to the instructions of the assay kit for ROS (chemical fluorescence method). The tendon samples were cut into pieces of $1 \mathrm{~mm}^{3}$, digested for $2 \mathrm{~h}$ with collagenase II at $37^{\circ} \mathrm{C}$ and cell pellet was collected after centrifugation for $5 \mathrm{~min}$ at $1500 \mathrm{rpm}$. Then, the collected cell pellet was added $1 \mathrm{~mL}$ of Dichloro-dihydro-fluorescein diacetate (DCFH-DA) which was diluted with serum-free medium to a final concentration of $10 \mu \mathrm{mol} / \mathrm{L}$, incubated for $30 \mathrm{~min}$ at $37^{\circ} \mathrm{C}$ and washed three times with serumfree medium. Before transferring to a 96-well plate, cells were centrifuged for $5 \mathrm{~min}$ at $1500 \mathrm{rpm}$ and resuspended in phosphate-buffered saline (PBS). Finally, the value of 

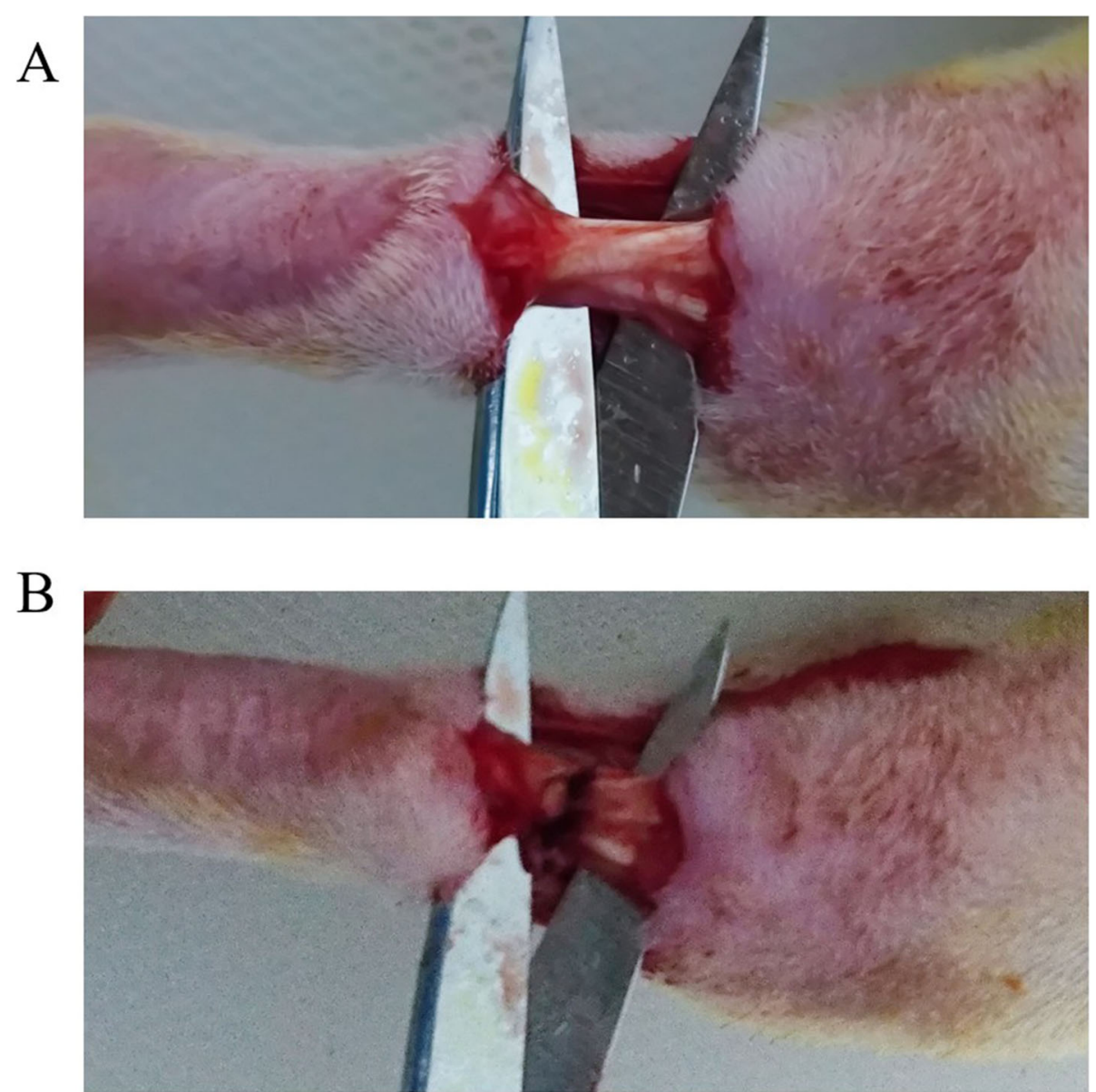

Fig. 1 a Achilles tendon was carefully dissected. b The tendon was restructured using modified Kessler's method after sharply severed

Table 1 Criteria for histological evaluation of peritendinous adhesion

\begin{tabular}{ll}
\hline Points & Features of adhesion \\
\hline 0 & Quantity \\
1 & No apparent adhesion \\
2 & A number of scattered filaments \\
3 & A large number of filaments \\
& Countless filaments \\
0 & Quality \\
1 & No apparent adhesions \\
2 & Regular, elongated, fine, filamentous \\
3 & Irregular, mixed, shortened, filamentous \\
& Dense, not filaments \\
0 & Grading of adhesion \\
$1-2$ & None \\
$3-4$ & Slight \\
$5-6$ & Moderate \\
\hline
\end{tabular}

each well was calculated by the fluorescence unit determined by a microplate reader at $488 / 525$.

\section{RNA isolation and qPCR}

RNA was extracted and purified from collected tendon tissues according to the manufacturer's instructions using EZ-press RNA purification kit (EZbioscience, MN, USA) and quantified through a spectrophotometer (Molecular Devices, CA, USA). cDNA was prepared by reverse-transcribing total RNA with the Double-Strand cDNA Synthesis Kit (Takara). All gene transcripts were quantified by Power SYBR Green PCR Master Mix (Takara) on the ABI StepOnePlus System (Applied Biosystems, Warrington, UK). The primer sequences were shown in Table 2. Expression levels were calculated using the relative quantitation method and gene expression was normalized to rat housekeeping gene GAPDH as previously reported [20].

\section{Histological evaluation}

The repaired Achilles tendon tissues harvested were fixed in $4 \%$ buffered formalin ( $\mathrm{pH}$ 7.4) and embedded in 
Table 2 Rat primers used in quantitative PCR analysis

\begin{tabular}{ll}
\hline Gene & Primer sequence(5'-3') \\
\hline IL-1 & Sense: GGGATGATGACGACCTGCTA \\
IL-6 & Antisense: TGTCGTTGCTTGTCTCTCCT \\
& Sense: CCACTGCCTTCCCTACTTCA \\
SOD1 & Antisense:TTCTGACAGTGCATCATCGC \\
& Sense: CACTTCGAGCAGAAGGCAAG \\
SOD2 & Antisense:CCAACATGCCTCTCTTCATC \\
& Sense: CACATTAACGCGCAGATCATG \\
COL1 & Antisense:CCTTAGGGCTCAGGTTGTC \\
& Sense: GGATCGACCCTAACCAAGGC \\
HIF1A & Antisense:GATCGGACCTTCGCTTCCA \\
& Sense: TGCTTGGTGCTGATTTGGA \\
GAPDH & Antisense: GGTCAGATGATCAGAGTCCA \\
& Sense:GAGCGAGATCCCGTCAAGATCAAA \\
& Antisense:CACAGTCTTCTGAGTGGCAGTGAT
\end{tabular}

paraffin blocks. Serial sections of 4 um were sliced and stained with hematoxylin and eosin (H\&E), and Masson staining. Preparations were viewed under an Olympus BX51 light microscope (Olympus; Tokyo, Japan) by two pathologists who were blinded to the design. Histologic grading methods were adopted to standardize the degree of adhesions and peritendinous inflammation among groups. The extent of adhesions was divided into four grades (1, no adhesions; 2 , slight adhesions; 3 , moderate adhesions; 4, severe adhesions) according to the criteria described by Tang et al. Peritendinous inflammatory reaction was classified into five grades ( 0 , no reaction; 1 , minimal leukocyte infiltration into fibro-osseous tendon sheath; 2, leukocyte infiltration in synovium and epitenon; 3, leukocyte infiltration in synovium and endotenon; 4, diffuse leukocyte infiltration) according to the criteria of Moran et al. [14].

For immunohistochemistry, sections were blocked with 5\% bovine serum albumin for $1 \mathrm{~h}$ and incubated with collagen I (COL1) antibody $(5 \mu \mathrm{g} / \mathrm{mL}$; Abcam), collagen III (COL3) antibody (1:100; Affinity Biosciences, USA) at $4{ }^{\circ} \mathrm{C}$ overnight. After primary antibody incubation, samples were exposed to Rabbit HRP Polymer (Biocare Medical). The bound antibody complex was visualized with diaminobenzidine then counterstained with hematoxylin. Stained sections were prepared and viewed under light microscopy. Micrographs were collected using a camera-assisted microscope (Nikon Eclipse microscope, model E6000 with an Olympus camera, model DP79).

\section{Statistical analysis}

All data were expressed as means \pm standard deviations. Student's $t$ tests were performed. Comparisons were made between surgery groups and control groups by analysis of variance. $P$ values $<0.05$ were considered significant.

\section{Results}

\section{Macroscopic findings}

All rats were observed to be in a healthy state and the skin wounds in every group recovered normally. No adhesion could be traced in the control and sham group. A gradual increasing trend of adhesion were seen from group 3 to group 6, while the biggest gap was observed between group 4 to group 5 which means the adhesion intensifies $48 \mathrm{~h}$ later after tendon repair. Table 3

\section{Inflammation}

All three inflammatory indicators followed a similar trend of rising in tendon surgery group as time passed. Both TNF- $\alpha$ and IL- $1 \beta$ rose significantly $24 \mathrm{~h}$ later after the tendon repair surgery compared with the control and sham group $(P<0.05)$, while the extent of TGF- $\beta 1$ statistically went up in $72 \mathrm{~h}$ after tendon surgery in the comparison with control and sham group $(P<0.05)$ (Fig. 2).

\section{Oxidative stress}

The reactive oxygen species (ROS) which was measured to indicate tissue oxidative stress ascended significantly $48 \mathrm{~h}$ later after the tendon surgery compared with the control and sham group $(P<0.05)$ (Fig. 2$)$.

\section{Uprising trends of mRNA expression}

qPCR analysis revealed a clear rising trend in inflammation, oxidative stress and fibrosis formation after tendon surgery in the first $72 \mathrm{~h}$. The expression of Interleukin$1 \beta$ (IL-1 $\beta$ ) and superoxide dismutase 2 (SOD2) in the experimental groups (groups $3,4,5$, and 6) were significantly higher than that in the control and sham group $(P$ $<0.05)$. Similar trend was seen in the expression of Interleukin-6 (IL-6) after 24 h. For superoxide dismutase 1 (SOD1) and collagen 1 (COL1), though the expression in experimental groups (groups 4, 5, and 6) were statistically higher than those of the control and sham group $(P$ $<0.01$ ), the uprising was gradual and accelerating after

Table 3 Grading results of macroscopic evaluation

\begin{tabular}{lllllll}
\hline & Group 1 (control) & Group 2 (sham) & $\begin{array}{l}\text { Group 3 } \\
\text { (6 h after surgery) }\end{array}$ & $\begin{array}{l}\text { Group 4 } \\
(\mathbf{2 4} \mathrm{h} \text { after surgery) }\end{array}$ & $\begin{array}{l}\text { Group 5 } \\
\text { (48 h after surgery) }\end{array}$ & $\begin{array}{l}\text { Group 6 } \\
\text { (72 h after surgery) }\end{array}$ \\
\hline Grading & 0 & 0 & 1 & 2 & 3 & 6 \\
\hline
\end{tabular}




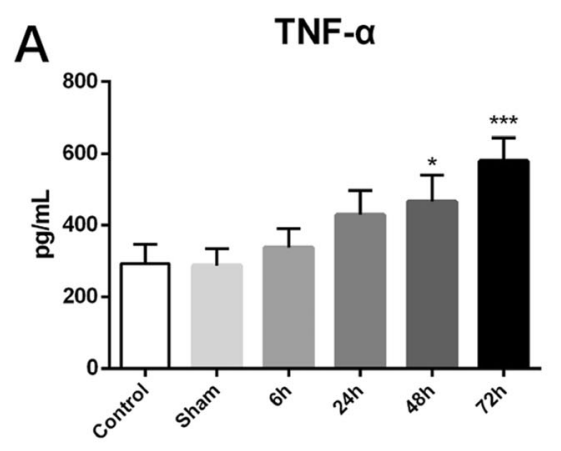

\section{IL-1 $\beta$}

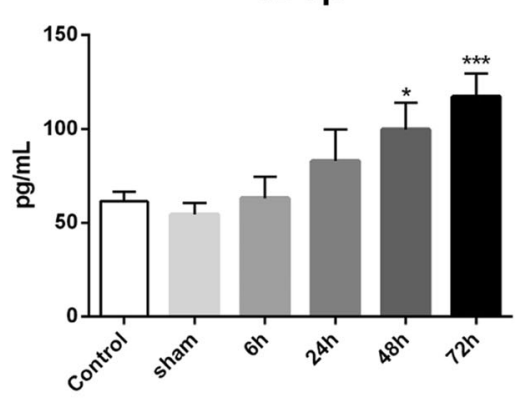

TGF- $\beta 1$

B

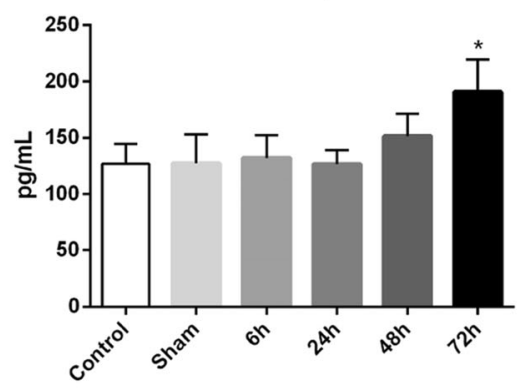

ROS

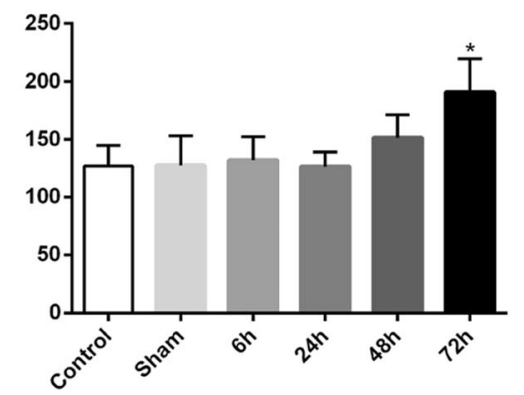

Fig. 2 a Respective trends of TNF- $\alpha$, IL-1 $\beta$, and TGF- $\beta 1$ in the serum with time.b Fluctuation of the serous content of ROS after tendon surgery ( * means $P<0.05$ when compared with control or group, ${ }^{* *} P<0.001$ )

$48 \mathrm{~h}$. The expression of hypoxia-inducible factor 1 alpha (HIF1A) was inversely proportional with SOD2 which indicated the dynamic situation of hypoxia and self-protection mechanisms by responsively raising SOD2. These results indicated that inflammation, oxidative stress, and fibrosis formation all gradually intensified in the very beginning. Thereinto, SOD1 and COL1, representing oxidative stress in cytoplasm and fibrosis formation, significantly ascended after $48 \mathrm{~h}$ (Fig. 3).

\section{Histological analysis}

Histological results gathered from every group are shown in Fig. 3. Both H\&E, Masson, and immunohistochemistry staining of COL1 and COL3 showed similar trends in histomorphology. No obvious peritendinous adhesion was observed in the control and sham group. The space around collagen fibers and peritendinous tissues was loose and clear. Collagen fiber hyperplasia and fibroblast proliferation were seen gradually increased from group 3 to group 6 . With time, inflammatory cells, vessels, and fibrous connective tissue infiltrated the tendon bundle. The thickest and firmest fibrous adhesion tissues developed at the repair sites in group 6. Semiquantitative scoring analysis showed a statistically significant rising in adhesion formation $48 \mathrm{~h}$ later after tendon repair surgery $(P<0.05)$.

\section{Discussion}

Peritendinous adhesion is one of the most common complications occurred during the healing process of injured tendon $[1,21,22]$. It binds the flexor tendons, restricts tendon gliding, and consequently leads to poor joint function [23, 24]. Numerous attempts have been explored to prevent adhesion formation [2-5, 7-10, 13, $14,21,25]$. For example, modified Kessler's method, improvements in surgical technique, was proved to decrease the adhesion formation by $134 \%[1,4]$. Other explorations, including local application of hyaluronic acid, 5-FU [5], etc. $[3,10]$. or physical barriers such as collagen membranes [26], PGA membranes [27], etc. [24] were proved to positively affect adhesion formation. However, the mechanisms underneath remain unclear.

ROS, by products of various enzymatic reactions, regulate cellular homeostasis and mediate both physiological and pathophysiological signal transduction [28]. They have been proved to be closely associated with metabolic regulation, including the emergence of atherosclerosis [29], diabetes [30], and stroke [31], and are mechanically known in response to inflammation [28, 32]. Thus, ROS was included in our study as a potential breach into the mechanisms of the repair of injured tendon.

Tendon injury means disruption to the original vasculature and the rapid influx of metabolically demanding cells in the following repair process of adhesion 


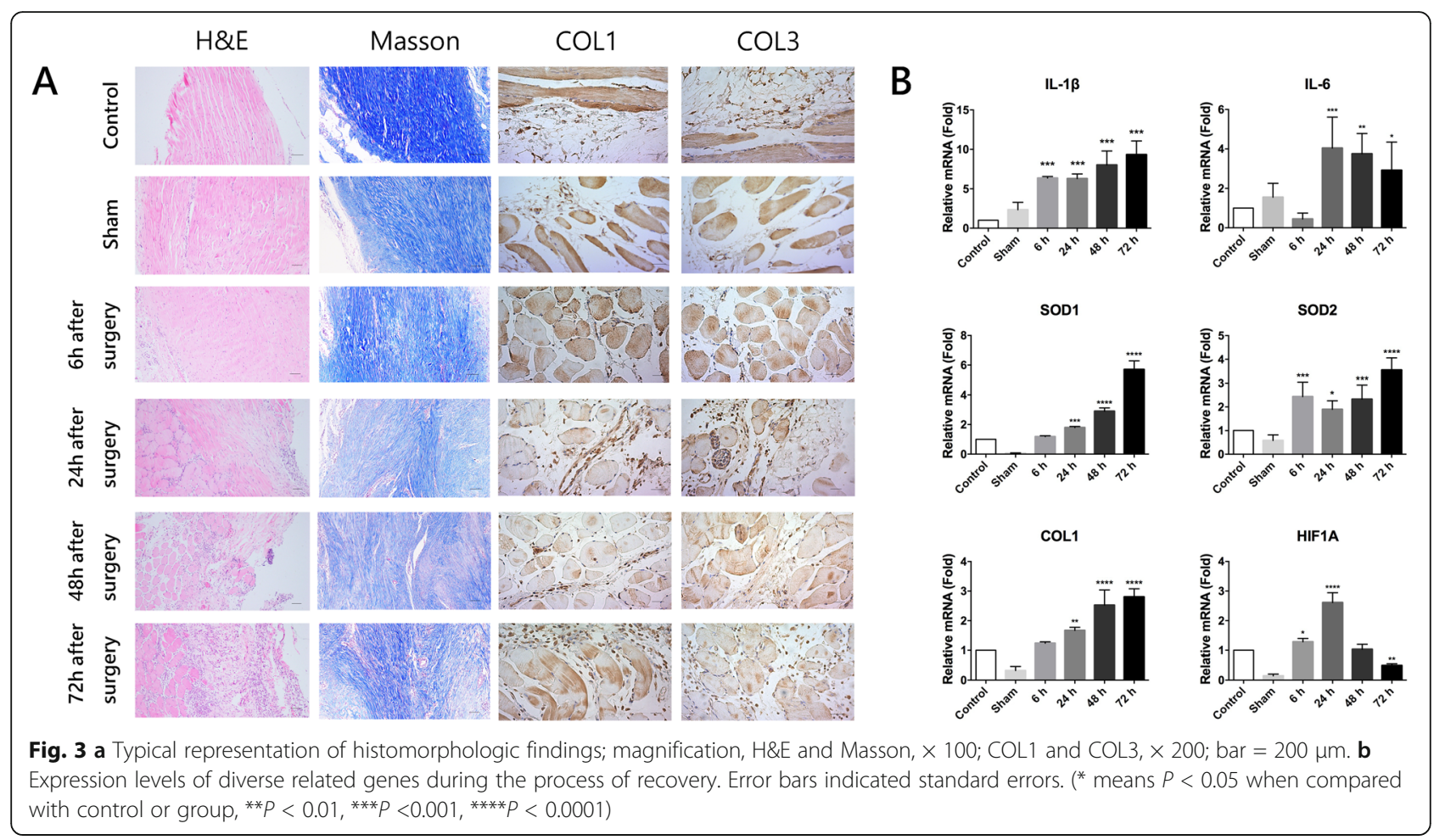

formation [16]. In other words, tissue hypoxia, inflammation, and oxidative stress are main vital issues needed to be handled to prevent fibrosis as soon as the injury occurs. From here, we designed the experiments to study the dynamic fluctuations and relationships within inflammation, oxidative stress, and adhesion formation. It is obviously seen from our results that the extent of TNF- $\alpha$, IL- $1 \beta$, and reactive oxygen species (ROS) in tendon surgery groups all rose up significantly $24 \mathrm{~h}$ later which demonstrated a close correlation between postoperative inflammation and oxidative stress. The excess TGF- $\beta 1$ after $72 \mathrm{~h}$, which could lead to chronic inflammation, fibrosis, and accumulation of extracellular matrix [33], undoubtedly played an important role in the formation of peritendinous adhesion. The expression levels of IL-1 $\beta$, IL-6, SOD1, SOD2, and COL1 all significantly ascended with time which confirmed the rising trend of inflammation, oxidative stress, and fibrosis formation. Expression of IL-1 $\beta$, IL-6, and SOD2, representing inflammation and oxidative stress in mitochondria, relatively rose in $24 \mathrm{~h}$ which suggested instant reaction in inflammation and oxidative stress. While SOD1 and COL1, symbols for oxidative stress in cytoplasm and fibrosis formation, significantly increased after $48 \mathrm{~h}$ indicating the expansion of oxidative stress and the intensification of fibrosis. Moreover, the expression level of HIF1A altered in an opposite trend when compared with SOD2, indicating the progressive relief of regional tissue hypoxia. As for the histological findings, inflammatory and fibrous infiltrations were gradually intensified in a time-dependent manner. However, serious peritendinous adhesion was seen $48 \mathrm{~h}$ later after tendon repair surgery which indicated fibrosis exacerbated after $48 \mathrm{~h}$. Combining all the results, it was deduced that in the first $24 \mathrm{~h}$ after tendon injury, vasculature loss and abrupt rising of metabolically demanding cells led to local tissue hypoxia which triggered following inflammation and oxidative stress. Under the influence of high levels of TNF- $\alpha$, IL-1 $\beta$, and reactive oxygen species (ROS), peritendinous adhesion emerges and aggravates in $48 \mathrm{~h}$. However, in this stage, the effects of TGF- $\beta 1$ were relatively minor until $72 \mathrm{~h}$. Though TNF- $\alpha$, IL- $1 \beta$, TGF- $\beta 1$, and ROS were all getting intensified over time, TNF- $\alpha$, IL- $1 \beta$, and ROS were quick to react, but TGF- $\beta 1$ mainly affected the fibrosis $48 \mathrm{~h}$ later after tendon injury. Based on our primary study on peritendinous adhesion formation, in the first inflammatory phase (24-48 h), cytokines like TNF- $\alpha$, IL-1 $\beta$, and reactive oxygen species were the main problems needed to be studied possibly through exploring the canonical NF- $\mathrm{KB}$ pathway [28, 32]. In the next phase of fibroblast proliferation (after 48 h), besides the inflammation and oxidative stress, TGF$\beta 1$ was participated in the accumulation of extracellular matrix and fibrosis through potential pathways including epithelial-mesenchymal transition, immunity, and stromal signaling, etc. [33]. In our previous researches in the mechanisms of tendon adhesion after injury, we found that over-expression of miR-29b could downregulate the 
expression of TGF- $\beta 1$ and Smad3 which aggravate adhesion [12]. Plus, application of Tanshinone IIA can inhibit the expression of TGF- $\beta 1$ and reduce collagen production in fibroblasts, thereby restraining tendon adhesions in rats [11]. Our study shined the directions in which the mechanisms of early stage peritendinous adhesion formation might lay. What is more, the late stage of tendon recovery in remolding phase is still waiting to be explored.

In the future, we can further explore the mechanisms of peritendinous adhesion by connecting the canonical NF- $\kappa B$ with TGF- $\beta 1 /$ Smad3 pathway, monitoring downstream expressions after regulation of target genes, and verifying in vivo by constructing a target gene knockout animal model.

\section{Conclusion}

Inflammation, oxidative stress in injured tendon resulted from acute trauma would be getting intense in $24 \mathrm{~h}$. Peritendinous adhesion emerges and aggravates after 48 h. Thus, prompt efficient measures are advised to be taken after the injury as soon as possible.

\section{Abbreviations}

ROS: Reactive oxygen species; ELISA: Enzyme-linked immunosorbent assay; TNF-a: Tumor necrosis factor alpha; IL-1B: Interleukin 1 beta; IL-6: Interleukin 6; TGF- $\beta 1$ : Transforming growth factor beta 1; COL: Collagen; SOD: Superoxide dismutase; HIF1A: Hypoxia-inducible factor 1-alpha; SD rats: Sprague-Dawley rats; PBS: Phosphate-buffered saline; DCFHDA: Dichloro-dihydro-fluorescein diacetate; GAPDH: Glyceraldehyde-3phosphate dehydrogenase

\section{Acknowledgements}

Not applicable

\section{Authors' contributions}

$\mathrm{HL}$ designed the study, performed data collection, and analyzed the results. Both PF L and HY Z drafted the manuscript, helped carry out the experiments, and analyzed the results. T T helped revised the manuscript and analyzed the results. All the authors have read and approved the final manuscript.

\section{Funding}

The National Natural Science Foundation of China (grant number 81702135) funded in the design of the study; Zhejiang Provincial Natural Science Foundation (LY20H060007) sponsored in the collection, analysis, and interpretation of data; Zhejiang Traditional Chinese Medicine Research Program (grant numbers 2016ZA124, 2017ZB057) funded the study in the writing part

\section{Availability of data and materials}

The datasets used and/or analyzed during the current study are available from the corresponding author on reasonable request.

\section{Declarations}

\section{Ethics approval and consent to participate}

The study protocols were approved by the Medical Ethics Committee of the First Affiliated Hospital of the College of Medicine, Zhejiang University (reference number: 2019(990)).

\section{Consent for publication}

Not applicable.

\section{Competing interests}

The authors declare that they have no competing interests.

\section{Author details}

${ }^{1}$ Department of Plastic and Aesthetic Center, The First Affiliated Hospital, College of Medicine, Zhejiang University, \#79 Qingchun Road, Hangzhou 310003, Zhejiang Province, China. ${ }^{2}$ Department of Orthopedics, The First Affiliated Hospital, College of Medicine, Zhejiang University, \#79 Qingchun Road, Hangzhou 310003, Zhejiang Province, China.

Received: 13 May 2020 Accepted: 22 April 2021

Published online: 05 May 2021

\section{References}

1. Dy CJ, Hernandez-Soria A, Ma Y, Roberts TR, Daluiski A. Complications after flexor tendon repair: a systematic review and meta-analysis. J Hand Surg. 2012;37(3):0-5510, 543, DOI: https://doi.org/10.1016/j.jhsa.2011.11.006.

2. Komurcu M, Akkus O, Basbozkurt M, Gur E, Akkas N. Reduction of restrictive adhesions by local aprotinin application and primary sheath repair in surgically traumatized flexor tendons of the rabbit. J Hand Surg. 1997;22(5): 826-32. https://doi.org/10.1016/S0363-5023(97)80076-7.

3. Dogramaci Y, Kalac A, Atik E, Esen E, Altuğ ME, Onel E, et al. Effects of a single application of extractum cepae on the peritendinous adhesion. Ann Plastic Surg. 2010;64(3):338-41. https://doi.org/10.1097/SAP.0b013e3181a fa428.

4. Khanna A, Friel M, Gougoulias N, Longo UG, Maffulli N. Prevention of adhesions in surgery of the flexor tendons of the hand: what is the evidence? Br Med Bull. 2009;90(1):85-109. https://doi.org/10.1093/bmb/ Idp013.

5. Fatemi MJ, Shirani S, Sobhani R, Lebaschi AH, Gharegozlou MJ, Bagheri T, et al. Prevention of peritendinous adhesion formation after the flexor tendon surgery in rabbits: a comparative study between use of local interferon- $a$, interferon- $\beta$, and 5-fluorouracil. Ann Plast Surg. 2018;80(2):1715. https://doi.org/10.1097/SAP.0000000000001169.

6. Karabagli Y, Ercel C, Kose AA, Oner U, Acikalin MF, Cetin C. Preventive effects of a turnover flexor tendon sheath flap on adhesion formation after flexor profundus tendon injury: an experimental study. J Plastic Reconstruct Aesthetic Surg. 2008;61(2):150-7. https://doi.org/10.1016/j.bjps.2007.05.010.

7. Liu Y, Skardal A, Shu XZ, Prestwich GD. Prevention of peritendinous adhesions using a hyaluronan-derived hydrogel film following partialthickness flexor tendon injury. J Orthopaedic Res. 2008;26(4):562-9. https:// doi.org/10.1002/jor.20499.

8. Bhavsar D, Shettko D, Tenenhaus M. Encircling the tendon repair site with collagen-GAG reduces the formation of postoperative tendon adhesions in a chicken flexor tendon model. J Surg Res. 2010;159(2):0-771, 765, DOl: https://doi.org/10.1016/j.jss.2009.10.010.

9. Ozgenel GYG. The effects of a combination of hyaluronic and amniotic membrane on the formation of peritendinous adhesions after flexor tendon surgery in chickens. J Bone Joint Surg Br Vol. 2004;86(2):301.

10. Karaaltin MV, Ozalp B, Dadaci M, Kayikcioglu A, Kecik A, Oner F. The effects of 5-fluorouracil on flexor tendon healing by using a biodegradable gelatin, slow releasing system: experimental study in a hen model. J Hand Surg Eur Vol. 2013;38(6):651-7. https://doi.org/10.1177/1753193412458646.

11. Lu H, Chen Q, Yang H, Shen H, Lin XJ. Tanshinone IIA prevent tendon adhesion in the rat achilles tendon model. J Biomaterials Tissue Eng. 2016; 6(9):739-44. https://doi.org/10.1166/jbt.2016.1502.

12. Chen $\mathrm{Q}$, Lu H, Yang H. Chitosan inhibits fibroblasts growth in Achilles tendon via TGF- $31 /$ Smad3 pathway by miR-29b. Int J Clin Exp Pathol. 2014; 7(12):8462-70

13. Tan V, Nourbakhsh A, Capo J, Cottrell JA, Meyenhofer M, O'Connor JP. Effects of nonsteroidal anti-inflammatory drugs on flexor tendon adhesion. J Hand Surg. 2010;35(6):0-947, 941, DOl: https://doi.org/10.1016/j.jhsa.2010.02. 033.

14. Moran SL, Ryan CK, Orlando GS, Pratt CE, Michalko KB. Effects of 5fluorouracil on flexor tendon repair. J Hand Surg. 2000;25(2):242-51. https:// doi.org/10.1053/jhsu.2000.jhsu25a0242.

15. Vincent $P$, Rémi M. Hypoxia-induced oxidative stress in health disorders. Oxidative Med Cell Longevity. 2012;2012:1-2.

16. Darby IA, Hewitson TD. Hypoxia in tissue repair and fibrosis. Cell Tissue Res. 2016;365(3):553-62. https://doi.org/10.1007/s00441-016-2461-3. 
17. Ray P, Huang B-W, Tsuji Y. Reactive oxygen species (ROS) homeostasis and redox regulation in cellular signaling. Cellular Signalling. 2012;24(5):981-90 https://doi.org/10.1016/j.cellsig.2012.01.008.

18. D'Autréaux B, TM. ROS as signalling molecules: mechanisms that generate specificity in ROS homeostasis. Nat Rev Mol Cell Biol. 2007;8(10):813-24.

19. Jin BT, Shi D, Zhang QG. Biomechanical and histologic evaluation of tendon sheath management. J Hand Surg Am. 1996;21(5):900-8.

20. Welch ID, Cowan MF, Beier F, Underhill TM. The retinoic acid binding protein CRABP2 is increased in murine models of degenerative joint disease. Arthritis Res Ther. 2009;11(1):R14. https://doi.org/10.1186/ar2604.

21. Meier Burgisser G, Calcagni M, Muller A, Bonavoglia E, Fessel G, Snedeker JG, et al. Prevention of peritendinous adhesions using an electrospun DegraPol polymer tube: a histological, ultrasonographic, and biomechanical study in rabbits. Biomed Res Int. 2014;2014:656240.

22. Lilly SI. Complications after treatment of flexor tendon injuries. J Am Acad Orthop Surg. 2006;14(7):387-96. https://doi.org/10.5435/00124635-2 00607000-00001

23. Pulos N, Bozentka DJ. Management of complications of flexor tendon injuries. Hand Clinics. 2015;31(2):293-9. https://doi.org/10.1016/j.hcl.2014.12. 004

24. Li Y, Weizhong Z, Xuanyi L, Mauro CF, Ke X, Erika L, et al. Controlled release of curcumin from curcumin-loaded nanomicelles to prevent peritendinous adhesion during Achilles tendon healing in rats. Int J Nanomed. 2016;11: 2873-81.

25. Zhou H, Jiang S, Li P, Shen H, Yang H, Xu S, et al. Improved tendon healing by a combination of Tanshinone IIA and miR-29b inhibitor treatment through preventing tendon adhesion and enhancing tendon strength. Int J Med Sci. 2020;17(8):1083-94. https://doi.org/10.7150/ijms.44138.

26. Zhao H, Guan HG, Gu J, Luo ZP, Qin S. Collagen membrane alleviates peritendinous adhesion in the rat Achilles tendon injury model. Chin Med J (Engl). 2013;126(4):729-33.

27. PihlajamKi H, Tynninen O, Karjalainen P, Rokkanen P. Enveloping bioabsorbable polyglycolide membrane and immobilization in achilles tendon repair: a comparative experimental study on rabbits. J Orthop Res. 2008;26(2):264-70. https://doi.org/10.1002/jor.20504.

28. Forrester SJ, Kikuchi DS, Hernandes MS, Xu Q, Griendling KK. Reactive oxygen species in metabolic and inflammatory signaling. Circ Res. 2018; 122(6):877-902. https://doi.org/10.1161/CIRCRESAHA.117.311401.

29. Jenkins RO, Zharkikh IL, Nadeev AD, Avdonin PV, Goncharov NV. Reactive oxygen species in pathogenesis of atherosclerosis. Curr Pharm Des. 2015; 21(9):1134-46. https://doi.org/10.2174/1381612820666141014142557.

30. Kaneto H, Katakami N, Matsuhisa M, Matsuoka TA. Role of reactive oxygen species in the progression of type 2 diabetes and atherosclerosis. Mediators Inflamm. 2010;2010:453892

31. Allen CL, Bayraktutan U. Oxidative stress and its role in the pathogenesis of ischaemic stroke. Int J Stroke. 2010;4(6):461-70.

32. Marui N, Offermann MK, Swerlick R, Kunsch C, Rosen CA, Ahmad M, et al. Vascular cell adhesion molecule-1 (VCAM-1) gene transcription and expression are regulated through an antioxidant-sensitive mechanism in human vascular endothelial cells. J Clin Invest. 1993;92(4):1866-74. https:// doi.org/10.1172/JCl1 16778.

33. Kim KK, Sheppard D, Chapman HA. TGF- $\beta 1$ signaling and tissue fibrosis. Cold Spring Harb Perspect Biol. 2018;10(4):a022293. https://doi.org/10.1101/ cshperspect.a022293.

\section{Publisher's Note}

Springer Nature remains neutral with regard to jurisdictional claims in published maps and institutional affiliations.

Ready to submit your research? Choose BMC and benefit from:
- fast, convenient online submission
- thorough peer review by experienced researchers in your field
- rapid publication on acceptance
- support for research data, including large and complex data types
- gold Open Access which fosters wider collaboration and increased citations
- maximum visibility for your research: over 100M website views per year
At BMC, research is always in progress.
Learn more biomedcentral.com/submissions

